\title{
Stellenbosch University: Africa's first WHO Bioethics Collaborating Centre
}

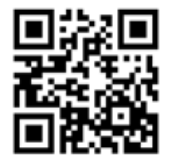

Stellenbosch University (SU)'s Centre for Medical Ethics and Law became Africa's first World Health Organization (WHO) Bioethics Collaborating Centre in April this year, after several years of working with the global body in vital areas such as vaccine policies, bio-banking and research ethics.

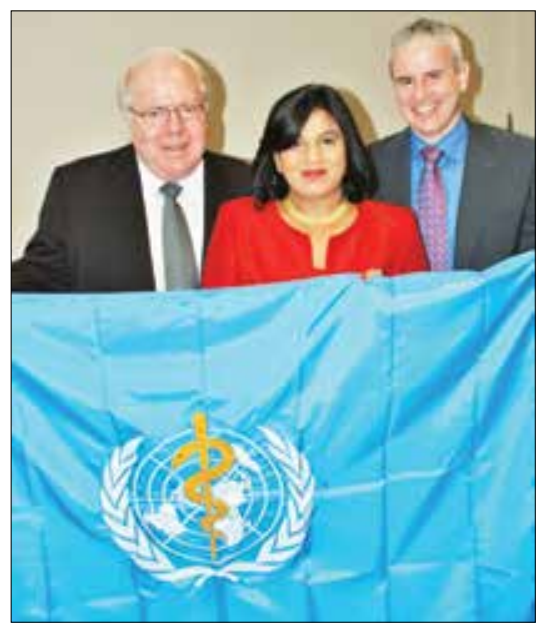

Prof. Anton van Niekerk, Director of Stellenbosch University's Centre for Applied Ethics, Prof. Keymanthri Moodley, Director of the SU Centre for Medical Ethics and Law, and Dr Andreas Reis of the World Health Organization.

It joins a prestigious international network of university bioethics centres in Toronto, New York, Zurich, Singapore, Miami and Melbourne which, among other things, informs the WHO's ethical understanding and response to global humanitarian crises such as the recent Ebola outbreak in West Africa. The collaboration will be renewable in 2019, with the current agreement being to cover ethical issues in neurological science and mental health (neuroimaging and dementia being of growing importance), and advising and developing guidelines on bio-banking and research ethics (with ongoing capacity-building workshops for the African region). The SU Centre has already played a pivotal role in developing $\mathrm{WHO}$ guidelines on ethical issues in public health surveillance. It will also monitor new issues in the local field as they arise.

Prof. Andreas Reis, strategy ambassador for strengthening and developing the WHO's regional institutional capacity and carrying out its mandated projects, said that the Ebola outbreak powerfully demonstrated the inherently global nature of ethics and the interconnectedness of all countries. "We can learn a lot from SA's concept of Ubuntu we'll only succeed globally if we build mutually beneficial partnerships.' He said that the Centre for Medical Ethics and Law, established in 2003, was one of the oldest and most prestigious in Africa, having built an excellent global reputation for empirical and conceptual research and medical ethics teaching, including a postgraduate diploma in research ethics, funded by the US National Institutes of Health. Prof. Jimmy Volmink, Dean in the Faculty of Medicine and Health Sciences, said that SU had a 'long and proud history' of partnership with the WHO, stretching over many decades. Its academic staff served on various WHO advisory boards and on several working groups, the most prominent being paediatric and drug-resistant tuberculosis (TB). Prof. Keymanthri Moodley, Director of the SU Centre for Medical Ethics and Law, was one of two SU academics in the WHO's Strategic Advisory Group of Experts (SAGE) on immunisation during humanitarian crises, and was currently part of the SAGE working group on Ebola vaccines. Other SU work that guided WHO policy formulation included the ongoing development of an HIV vaccine, health systems strengthening, prevention of mother-to-child HIV transmission and adherence to antiretroviral and TB drugs. Volmink singled out philosophy professor Anton van Niekerk, Director of SU's Centre for Applied Ethics, as 'one of the fathers of bioethics' in SA, saying he played a leading role in teaching and mentoring several clinicians/bioethicists who contribute to teaching in the Centre.

Van Niekerk told the gathering that bioethics had (belatedly) come a long way since Chris Barnard's heart transplant, which would have 'failed dismally' to clear today's ethical hurdles (i.e. the definition of death). 'Bioethics was not taken seriously before the 1980s [in SA]; the attitude was that it was important, but taught by the bedside with no serious need for the philosophical underpinnings - you could get around it by simply making it a practical subject.' The pivotal and founding local event for bioethics in SA was the death of Steve Biko in December 1977.
Together with the Soweto uprising in June 1976, these deaths made it clear that the rhetoric of government leaders about the intended justice of the homeland system and other alleged justifications for apartheid were bogus and that the system was morally corrupt with its demise 'a mere matter of time. The Biko affair highlighted the importance of a moral orientation in the practice of medicine and directly contributed to a reorganisation of the institutionalised medical profession in SA. Greater attention to ethical responsibilities towards prisoners, detainees and hunger strikers ensued, while the public confession of guilt by the district surgeon who bore major responsibility for Biko's medical care emphasised the need to maintain professional independence in the face of state security and other coercive pressures. Biko's death highlighted the depths to which a society could sink when gross violations of human rights became commonplace, and illustrated the social and political impact that a severe violation of medical morals had on SA society.

Van Niekerk said the teaching of bioethics, while not progressing equally across medical faculties, had increased profoundly in the past 20 years, particularly since it was introduced into healthcare worker undergraduate education in the late 1990s. HIV/AIDS had raised a 'host' of bioethical issues, not to mention $\mathrm{TB}$ and malaria, making SA a leading international destination for biomedical researchers. He paid tribute to the contribution of Ethics SA's Prof. Willem Landman and his empirical research on the state of the medical profession in SA and the appalling conditions in several major hospitals, and said that Ethics SA had also changed the face of abortion in SA by helping introduce the Termination of Pregnancy Act (1996), which remained one of the most liberal laws in the world. The draft law on assisted death, tabled by the Law Commission in Parliament in 1998, was shelved by government but still contained 'some remarkable suggestions' which would have to be confronted 'sooner or later. The National Research Ethics Council had produced outstanding and long-awaited revised guidelines for ethical research that had been 'signed off' by the health minister and his director-general, now probably due for publication next year.

Moodley said her journey to Director of the Centre began in 1997 when she was a 


\section{BREATHE BETTER, SLEEP BETTER.}

Otrivin $^{\circledR}$ helps your breathe better for up to 12 hours so you can sleep better to be your best the next day.

Because tomorrow starts tonight.

- 2-in-1 moisturising formula

- Rapid-acting nasal spray'

- Otrivin ${ }^{\circledR}$ Paediatric Spray \& Drops suitable for children from 2 years

Let the nose do the breathing Reference: 1. Eccles R, Martensson K, Chen SC. Effects of intranasal xylometazoline, alone or in combination with ipratropium, in patients with common cold. Curr Med Res Opin 2010; 26(4): 889-899.

51 Otrivin Adult drops. Each $1 \mathrm{ml}$ contains $1 \mathrm{mg}$ of xylometazoline hydrochloride. Preservative: benzalkonium chloride $0.011 \% \mathrm{~m} / \mathrm{v}$. Reg. no:: $\mathrm{H} / 16.1 / 1382$. [1] Otrivin ${ }^{\oplus}$ Adult Metered-dose spray. Each $1 \mathrm{ml}$ contains $1 \mathrm{mg}$ of xylometazoline hydrochloride. Preservative: benzalkonium chloride $0.011 \% \mathrm{~m} / \mathrm{v}$. Reg. no.: H/16.1/1382. [1] Otrivin Menthol ${ }^{-1}$ Metered-dose spray. Each $1 \mathrm{ml}$ contains $1 \mathrm{mg}$ of
xylometazoline hydrochloride. Preservative: benzalkonium chloride $0.01 \% \mathrm{~m} / \mathrm{v}$. Reg. no.: $31 / 16.10319$. 51 Otrivine Paediatric drops. Each $1 \mathrm{ml}$ contains $0,5 \mathrm{mg}$ of xylometazoline hydrochloride. Preservative: benzalkonium chloride $0.011 \% \mathrm{~m} / \mathrm{v}$. Reg. no.: H/16.1/1381. 51] Otrivin Paediatric Metered-dose spray. Each $1 \mathrm{ml}$ contains $0,5 \mathrm{mg}$ of xylometazoline hydrochloride. Preservative: benzalkonium chloride $0.011 \% \mathrm{~m} / \mathrm{v}$. Reg no.: H/16.1/1381. For further information contact Novartis Consumer Health.

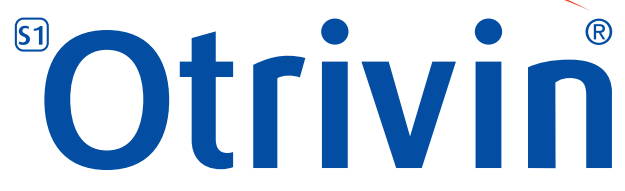


new consultant to Prof. Pierre de Villiers, then head of the Department of Family Medicine at SU. 'He gave me a huge pile of folders and told me to prepare two ethics lectures for fifth-year medical students, unschooled as I was in medical ethics. I took it on as a challenge.' By the following year she realised she needed 'much greater depth of knowledge in ethics' and studied philosophy under Van Niekerk, 'thinking about value systems and morality', before going to Columbia University in New York as a Fogarty Fellow. In the midst of the Twin Towers 9/11 tragedy, she studied public health ethics with Prof. Ron Bayer (who now chairs the global network of WHO collaborating centres in bioethics). He encouraged her to start working on her doctorate. Upon her return to SA she approached Prof. Wynand van der Merwe, then Dean of SU's Faculty of Medicine, suggesting the establishment of a SU Centre for Bioethics. He and Prof. Barney de Villiers (now deceased) made the Centre into a reality. Together with Profs Willie
Pienaar and Sharon Kling, Moodley has built a strong and dynamic undergraduate ethics programme, with several fifth-year medical students today regarding their ethics block as 'among the most stimulating' because it teaches them 'to think and challenge'.

\section{Chris Bateman}

chrisb@hmpg.co.za

S Afr Med J 2015;105(6):430-431.

DOI:10.7196/SAMJ.9748

\section{Healthcare workers baulk at caring for contagious patients}

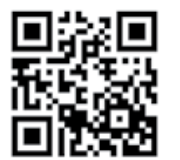

Globally, healthcare workers (HCWs) are reluctant to care for highly infectious patients, with over half surveyed in the USA saying it was acceptable not to pitch up for work during an outbreak of (for example) avian flu, World Health Organization (WHO) surveys show.

Dr Andreas Reis, strategy ambassador for strengthening and developing the WHO's regional institutional capacity and carrying out its mandated projects, said there were widely differing country attitudes to the vexed question of HCWs exposing themselves to high-risk infection. He was speaking after a ceremony on the Tygerberg campus of Stellenbosch University designating its Centre for Medical Ethics and Law as a WHO Collaborating Centre. Reis said that in Taiwan, China, about $57 \%$ of nurses indicated that they were willing to care for patients infected with avian flu, the perception of the importance of their role being the most influential factor. However, in Germany this figure rose to $72 \%$, while just $28 \%$ agreed that it would be professionally acceptable to abandon their workplace in order to protect themselves and their families. Most German HCWs (58\%) did not believe that the decision to report to work during a pandemic should be left to the individual HCW, yet $77 \%$ of them disagreed that HCWs should be dismissed for not reporting to work. In Canada, doctors who wanted to abandon posts during the 2003 outbreak of severe acute respiratory syndrome (SARS) in Toronto faced threats of ostracism.

Reis said that the American Nurses' Association's advice to HCWs was 'to engage in critical thinking and ethical analysis'. Arguments for a moral obligation included an HCW's ability to provide care being greater than that of the public, that they freely chose their profession knowing it had inherent risks, and that there was an unspoken social contract. However, limits and conflicts included the dual role of caring for oneself and one's family and the balance of immediate benefits to individual patients with the ability to care for patients in the future. Governments and employers had a reciprocal obligation to minimise the risk to HCWs. These included ensuring adequate infection control systems, providing preventive measures (e.g. pharmaceuticals, personal protective equipment), and taking a stand on the thorny issue of whether HCWs should have preferential access to experimental drugs, or receive priority treatment, prophylaxis or vaccines. Yet another obligation included putting in place death and disability benefits for HCWs.

\section{Human resources key to any humanitarian response}

Reis said that sufficient human resources formed the foundation of any effective response to a humanitarian crisis. The 2013 WHO report 'A Universal Truth: No health without a workforce' showed that there was a global shortage of almost 7.2 million doctors, midwives and nurses, plus healthcare support staff. This figure is likely to grow to nearly 12 million in the next 18 years. He said that the concept of ethical duties was formally introduced in the USA in 1847 in 'fairly absolute terms', with the American Medical Association declaring 'when pestilence prevails it is the physician's duty to face the danger, even at the jeopardy of his or her own life. By the 1980s, with the advent of HIV/AIDS, vigorous debate about the duty to care gave rise to more sophisticated and subtle approaches. These resulted in moral, professional, contractual,

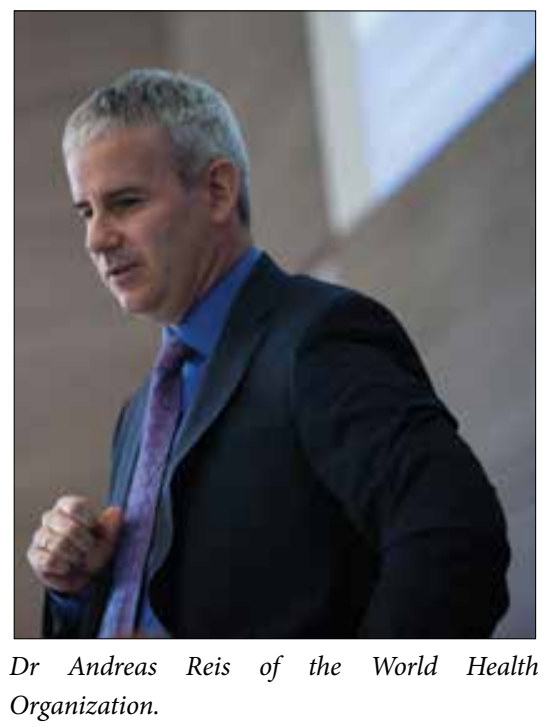

voluntary and legal obligations, none of them mutually exclusive or interdependent.

Prof. Anton van Niekerk, Director of Stellenbosch University's Centre for Applied Ethics and Chairperson of its Department of Philosophy, said that the real question was the level and intensity of risk that HCWs were prepared to face. He defined a 'risk decision' as being based on a balance between beneficial and adverse outcomes, adding that it was 'an irony of the modern world that just when we thought we had serious disease more or less under control, AIDS pops out, followed by SARS and now Ebola; who knows what's around the next corner? For example, what are the possible implications of climate change in terms of disease and the availability of nourishment?' HCWs had been running personal risks since the time of the Good Samaritan - the prototype of the 'good doctor', who even paid the innkeeper to care for the injured man. However, 


\section{Triple Therapy Trivenz}

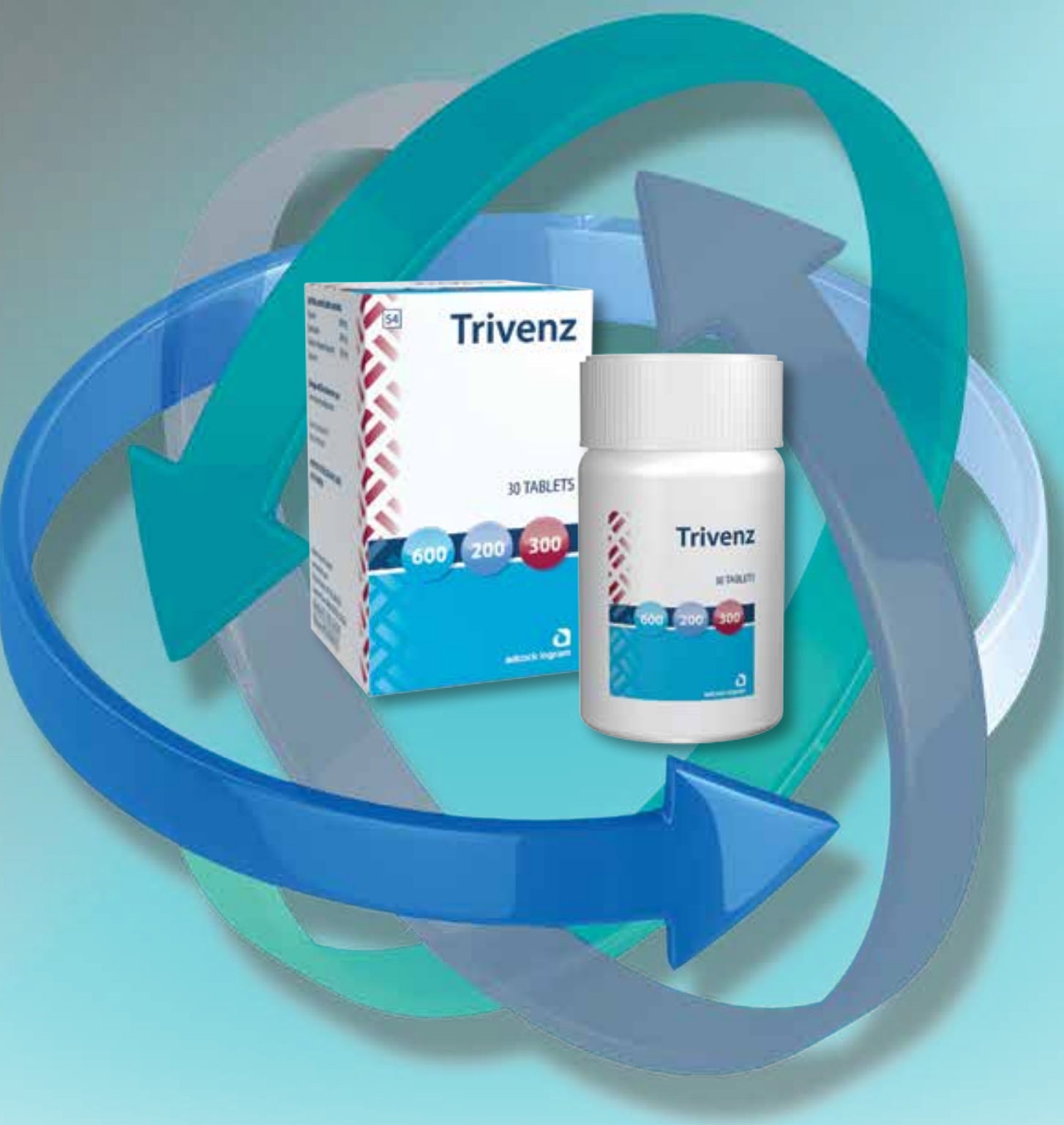

Efavirenz + emtricitabine + tenofovir disoproxil fumarate in a fixed dose combination for improved adherence and compliance. ${ }^{1,2}$

\section{Adcock Ingram, committed to the treatment of HIV}


professionalism (also among police, soldiers, fire-fighters and lifesavers) implied specialised skills that certain emergency situations called for. A high premium was placed on HCWs duty to their patients, particularly when those patients were completely dependent on medical professionals (he cited surgeons and anaesthetists). He drew a distinction between actual and prima facie duties, the former being what one 'should' do (a moral decision/action) and the latter a conditional duty that one fulfilled, unless it conflicted with an equal or stronger obligation. Van Niekerk argued that there was no 'absolute duty of care'. However, a catastrophic humanitarian crisis was a typical example of a prima facie duty that could only be determined once all the relevant factors had been considered.

\section{In Taiwan, China, about 57\% of nurses indicated that they were willing to care for patients infected with avian flu, the perception of the importance of their role being the most influential factor. However, in Germany this figure rose to $72 \%$.}

\section{South Africa void of 'duty to care' directives} Van Niekerk said he could find 'little or nothing' in terms of South African directives about the duty to care in high-risk situations. The Constitution, while stating that nobody may be refused emergency medical treatment (Article 27, which the South African Medical Association endorsed), dealt mainly with basic rights such as health, food, water and social security. The Health Professions
Council of South Africa guidelines for good practice urged HCWs to 'act quickly to protect patients from risk' if they believed they were impaired, while providing healthcare within the scope of the HCW's practice, experience and competencies in emergency situations. If unable to do this, they were advised to refer the patient to a colleague or facility where the required care could be provided. Van Niekerk wryly commented that 'this becomes a bit moot in West Africa's Ebola areas'.

Health catastrophes that imposed the risk of infection, serious illness and the possible death of HCWs could 'clearly' not be regarded as requiring an absolute obligation on their part. Services in such situations 'can and must only be voluntary'. Factors that played a role in deciding the need and efficacy of care in such situations included where the HCWs worked, what their specialty was, whether patients would actually benefit, and whether it was worth while risking HCW lives for people who would die in any case. 'My argument is that the over-riding moral concern is consent and never coercion', he added. Van Niekerk stressed that the time to decide one's level of commitment in the face of threats to personal safety was not during a public health emergency, but beforehand. Backing Reis's earlier input, he said that policies became paramount in supporting HCWs to reach a decision themselves. This involved careful evaluation of suitable candidates (did they have dependents, their general psychological disposition, levels of adherence to rules and regulations, i.e. no 'cowboys'), optimal knowledge of the crisis and 'risk-required' behaviour, optimal resources, remunerative support (i.e. danger pay), and realistic expectations from patients.

\section{The tragic vaccination lesson of Haiti}

Prof. Dave Durrheim, Director of Public Health Medicine at the University of Newcastle in New South Wales, Australia, said that the first time ethical issues were made as important as any others was after the 'colossal wake-up call' of the January 2010 Haiti earthquake, which was immediately followed by a highly destructive hurricane. The double blow cost 220000 lives with 300000 injuries. He said that humanitarian workers brought cholera with them and the national government dithered on making a decision about oral vaccination, miring itself in political rationalisation. By the end of last year 700000 cholera cases had been confirmed, with 10000 deaths. 'How many lives could have been saved we'll never know, but it illustrates the point that a much more generic response is required,' he said.

Asked about the WHO's tardy response to Ebola in West Africa (i.e. only when international containment became an issue), Reis reluctantly agreed, adding that many infectious diseases were confined to poorer countries ' with a lack of market to develop drugs and vaccines for these neglected diseases.' 'It's very important to create new mechanisms and markets to develop these, not only for Ebola but other tropical diseases. That will prove key', he said. The World Bank was trying to implement a policy of universal health coverage 'with ongoing planning and programmes to raise the general level of health and surveillance systems to enable better preparedness', he added.

\section{Chris Bateman}

chrisb@hmpg.co.za

S Afr Med J 2015;105(6):431-432.

DOI:10.7196/SAMJ.9749

\section{Judge nudges dormant euthanasia draft law}

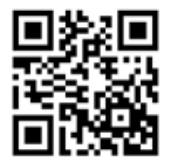

A terminally ill Cape Town advocate who died of natural causes hours before a Gauteng High Court judge granted him the locally unprecedented right to end his life (or have a doctor help him end it) may have speeded up long-recommended progressive law more in line with provisions of the Constitution.

Judge H J Fabricius of the Pretoria Division of the Gauteng High Court this April supported the 'development' of common law that predates the Bill of Rights and outlaws euthanasia. He said that serious consideration of new legislation based on the 1998 recommendations of the South African Law Commission was needed to bring the existing law more in line with constitutional provisions. The 1998 commission found in favour of euthanasia, as long as safeguards were in place to ensure that only terminally ill people in a sound state of mind could request and receive it. However, for 16 years Parliament has failed to act upon or even debate its recommendations.

Judge Fabricius's ruling - and the revival of the complex and hotly contested euthanasia debate - could be the catalyst that leading academics in bioethics and philosophy have been waiting for to enable a more pragmatic and human rights-based approach to severe, prolonged and unnecessary human suffering. The judge stressed that his ruling applied only to retired advocate Robin Stransham-Ford, who was 65 , and did not change any existing laws prohibiting euthanasia, which would need to be challenged on the individual merits of each case. Assisted suicide or active voluntary euthanasia remains unlawful.

\section{Suffering patient 'totally rational', wanted to die on his terms}

He said Stransham-Ford, who was suffering from terminal stage 4 cancer with only weeks to live, was highly qualified, 'of vast 
experience' in the legal profession and knew exactly what he required and why. The applicant was psychologically assessed and found to have no cognitive impairments; 'in fact he impressed as being totally rational'. He had a good understanding and appreciation of the nature, cause and prognosis of his illness, plus the clinical, ethical and legal aspects of assisted suicide.

Stransham-Ford suffered from severe pain, nausea, vomiting, stomach cramps, constipation, disorientation, weight loss, loss of appetite, high blood pressure and increased weakness and frailty related to his kidney metastases. He was unable to get out of bed and had injections and drips. Unable to sleep without morphine or other painkillers, which made him drowsy, he endured anxiety related to dying while suffering, although he was not afraid of death itself. Lawyers for Stransham-Ford argued that, from a philosophical point of view, there was no difference between assisted suicide by providing the sufferer with a lethal agent or switching off a life-supporting device - or the injecting of a strong dose of morphine with the intent to relieve pain and knowing that the respiratory system would close down, leading to death. Stransham-Ford said in his affidavit that there was no logical distinction between withdrawing treatment to allow 'the natural process of death' and physician-assisted death, labelling this distinction 'intellectually dishonest'. Judge Fabricius said that while there was 'much to be said' for this view, he would 'leave it for the philosophers' and confine himself to the constitutional debate.

\section{Stransham-Ford said in his affidavit that there was no logical distinction between withdrawing treatment to allow' the natural process of death' and physician-assisted death, labelling this distinction 'intellectually dishonest'.}

\section{Sacredness of the quality of life}

The right to life was at the centre of South Africa's constitutional values, establishing a society where the individual value of each community member was 'recognised and treasured', and therefore incorporated the right to dignity. Without dignity, human life was substantially diminished. 'I also agree with the warning that any pious uncoupling of moral concern from the reality of human and animal suffering has caused tremendous harm to mankind throughout the centuries.' Judge Fabricius said he agreed with Stransham-Ford's contention that it was a fundamental human right to die with dignity, which the country's courts were constitutionally obliged to advance, respect, protect, promote and fulfil. Contrary to what the respondents (the Minister of Justice and Correctional Services, the Minister of Health, the Health Professions Council of South Africa and the National Directorate of Public Prosecutions, plus Doctors for Life, admitted as 'friends of the court') had submitted, the sacredness of the quality of life should be accentuated rather than the sacredness of life per se. The norms of the Constitution should inform the public and its values, 'not sectional, moral or religious convictions'.

Judge Fabricius said it was 'unfortunate and disturbing' that societies acquiesced in thousands of deaths caused by weapons of mass destruction. They even seemed to tolerate a 'horrendous' murder rate, the 'daily slaughter on our roads', impure water and insufficient medical facilities. 'The state says it cannot afford to fulfil all socialeconomic demands, but it assumes the power to tell an educated individual of sound mind who is gravely ill and about to die that he must suffer the indignity of the severe pain, and is not allowed to die in a dignified quiet manner with the assistance of the medical practitioner.' The judge said an irony was that 'we are told from childhood to take responsibility for our lives, but when faced with death we are told we may not be responsible for our own passing ... one can choose one's career, decide to get married, live according to a lifestyle of one's choosing, consent to medical treatment or refuse it, have children and abort children, practise birth control, and die on the battlefield for one's country. But one cannot decide how to die.' The choice of Stransham-Ford was consistent with an open and democratic society and its values and norms as expressed in the Bill of Rights. There was 'of course' no duty to live, and a person could waive his or her right to life.

\section{Inevitable abuse \\ 'unlikely' - Judge}

Judge Fabricius emphasised that any future court could determine the necessary safeguards 'on its own facts', saying that there was therefore no 'uncontrolled ripple effect', as was put to him by the respondents. He also disagreed with the respondents that his

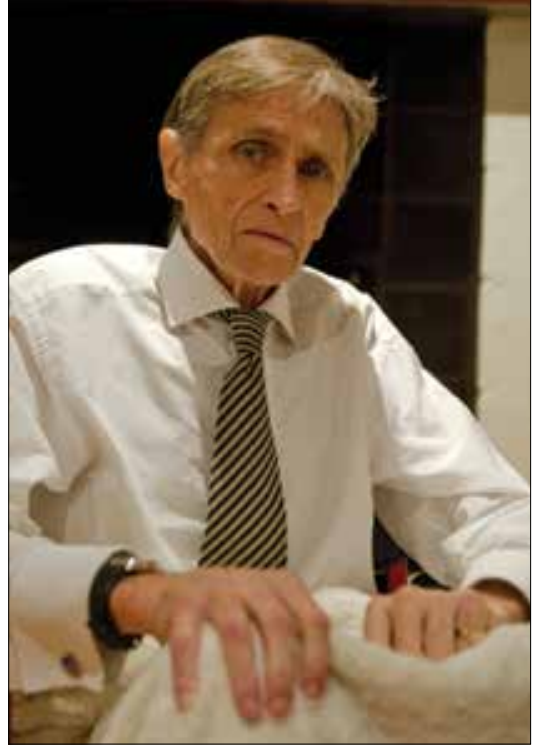

Terminally ill retired advocate Robin StranshamFord. Photo courtesy of Gallo Images, by Jaco Marais of Die Burger.

facts-based development of the common law would 'leave a void that will inevitably lead to abuse'. While the Ministry of Justice and Correctional Services attributed the original lack of action on the Law Commission's report to 'other priorities such as HIV and the AIDS epidemic', it did not say why the report was given no subsequent legislative attention.

The South African Medical Association (SAMA) Human Rights, Law and Ethics Committee cautioned health practitioners that the HPCSA's policies remained in force and said that 'any such activities' could result in disciplinary sanctions. It highlighted that the order applied 'only to this index case'. The committee emphasised the value of palliative care for the relief of pain and suffering for patients who were terminally ill and stressed that 'pain cannot be viewed as persuasive enough reason to resort to the extreme measure to end one's life'. SAMA did not support the right to die in law, euthanasia or doctorassisted suicide, which was in line with the HPCSA's Policies and the World Medical Association's Guidelines and codes on the subject.

The respondents have filed appeals against the ruling, paving the way for a potentially even more far-reaching Constitutional Court ruling.

\section{Chris Bateman}

chrisb@hmpg.co.za

S Afr Med J 2015;105(6):432-433

DOI:10.7196/SAMJ.9789 


\section{The Fabricius decision on the Stransham- Ford case - an enlightened step in the right direction}

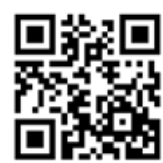

Many diseases are associated with incredible pain and suffering. Others impair function and independence to the extent that human dignity is eroded. In many instances the natural history of such conditions often leads to death within a reasonable period of time. In some cases, protracted ill health, pain, suffering and indignity ensue. Such circumstances have since time immemorial triggered the debate on euthanasia - a debate on what it means to have a good death. Acting compassionately, many South African (SA) doctors have, to some extent, either passively or actively assisted patients in achieving a good death.

\section{Ending a tormented existence}

In recent times, evolving expertise in the medical profession and some technological advances in medical science have inadvertently created the need for assisted suicide. We have found ways to artificially prolong existence at the expense of quality of life, independence and dignity. We 'play God' each time we intervene to interrupt the natural progression of disease. Although we primarily intend to act beneficently, we do inadvertently cause harm. Many of our medical and surgical interventions, particularly in the field of oncology, have adverse events that cause incredible suffering in the hope of prolonging life. Such suffering often results in patients choosing death over a severely eroded quality of life. Surely the rights of patients who are enduring unbearable suffering, indignity and pain must be respected, even if this includes the expression of their right to die? Compassion, a primal virtue of the profession, demands that we respect the wishes of patients who choose to end a tormented existence of pain, indignity and dependence. Against this background, I am extremely pleased with the Fabricius judgment in respect of the recent Stransham-Ford case.

However, it is clear that my opinion is not shared by the South African Medical Association, the Health Professions Council of South Africa or the Ministry of Health - all major opponents of the Fabricius ruling. Arguments against legalising assisted suicide in SA have included cultural and religious objections, professional duties and moral obligations of doctors and the classic 'slippery slope'

\section{'Cultural resistance' untested}

Assisted suicide may be perceived as the ultimate expression of liberal individualism, a phenomenon common to urban, so-called Western societies. Some have argued that culturally, only a segment of the SA population will support assisted suicide. While this may be true, to a large extent this view remains untested. We have no empirical evidence to support this assertion. It is well documented that African philosophy supports the concept of communal good rather than individual good. However, is this a phenomenon of traditional rural communities only, or does it apply to urban communities as well? The Bill of Rights enshrined in the Constitution is firmly rooted in the tradition of liberal individualism, and the rest of our existing health legislation in the form of statutory law strongly supports individual patient choice, from as early as the age of 12 years - individual informed consent, privacy, confidentiality, truth-telling, and ultimately choice on termination of pregnancy. SA women of all cultural and ethnic origins exercise individual choice every time they opt for a termination of pregnancy, often without consent from the father of the child or the extended family. Do we hear arguments about Ubuntu being advanced with respect to these pieces of legislation that are firmly entrenched in SA society? Admittedly many unexplored religious and cultural views exist with respect to assisted suicide. Many questions remain unanswered.

Professional duties of doctors require that they promote life and prevent harm. According to the World Medical Association Declaration on Terminal Illness, adopted in 1983 and revised in 2006, the 'duty of physicians is to heal, where possible, to relieve suffering and to protect the best interests of their patients. This statement in and of itself does not exclude assisted suicide, which is intended to relieve suffering and to protect the best interests of the patient. The declaration goes on to assert that the patient's 'right to autonomy in decisionmaking must be respected with respect to decisions in the terminal phase of life'. This right to autonomy is, however, restricted to refusal of treatment and requesting palliative treatment to relieve suffering that may have the additional effect of accelerating the dying process - the doctrine of double effect. The right to assisted suicide, which would otherwise be included in the patient's right to autonomy in end-oflife decision-making, is excluded. However, legally this could be regarded as exculpatory language - use of language that limits or waives the rights of patients.

\section{Surely the rights of patients who} are enduring unbearable suffering, indignity and pain must be respected, even if this includes the expression of their right to die? Compassion, a primal virtue of the profession, demands that we respect the wishes of patients who choose to end a tormented existence of pain, indignity and dependence.

\section{No 'slippery slope'}

The classic 'slippery slope' argument has been advanced by others, with opinions on the euthanasia legislation in the Netherlands presented as evidence. While the Dutch legislation around euthanasia has been based on strict criteria limited to terminal illness only since 2002, recent reports indicate that some doctors are bending the rule and extending the criteria to include less severe forms of illness. There are therefore allegations that some Dutch doctors are treading down the proverbial slippery slope. This is to be expected in a minority of members of the profession in any country - members who cross boundaries in various other aspects of professional conduct too - and legislation should be in place to sanction such transgressions via professional bodies and via the courts. We can learn from the Dutch experience and ensure that the necessary safeguards are built into our end-of-life legislation, such that assisted suicide is an option of last resort. Careful and robust construction of legislation around assisted suicide must therefore make provision for extremely strict criteria, as outlined by the South African Law Commission in 1999. The Death with Dignity Act has been in place in Oregon in the USA for the past 17 years, and unlike the controversial Dutch legislation, appears to be more robust. Finally, legislation merely creates options that can only 
be exercised by patient choice. Assisted suicide does not imply that doctors can force this option onto patients. Our National Health Act supports informed consent, which guards against doctors imposing treatment of any sort on patients. The Act also supports refusal of treatment options recommended by a doctor. Likewise, not all doctors have to participate in assisted dying. The option of conscientious objection by doctors must be included in such legislation.

\section{Concluding thoughts}

Assisted suicide is an emotive topic that is ethically, legally and culturally challenging. Views of all relevant stakeholders must therefore be explored before general legislation can be introduced. Resolving these questions requires intense community engagement, a process that can be initiated via empirical research. However, research can be a slow, costly and challenging process. If the question of assisted suicide is deemed a serious enough matter, a referendum could be held to test societal views in SA on this extremely contentious issue. Until such data are obtained, requests should be treated on a case-by-case basis, as has occurred in the Stransham-Ford matter.
In societies that are allowed to exercise choice in virtually all domains of their lives, limiting autonomy at the end of life is at best myopic and represents the last remnants of paternalism in healthcare.

\section{Keymanthri Moodley}

Director, Centre for Medical Ethics and Law, Stellenbosch University, Tygerberg, Cape

Town, South Africa

km@sun.ac.za

S Afr Med J 2015;105(6):434-435

DOI:10.7196/SAMJ.9790

\section{Robotic computer system develops high-skill 'technosurgeons'}

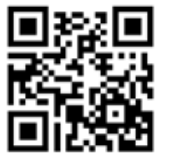

Just 15 months after four highly sophisticated robotassisted da Vinci Surgical Systems were introduced to South Africa (SA), nine local urologists are now 'flying' the ZAR23 million devices 'solo', while another ten are being mentored on the revolutionary robotic-assisted laparoscopic tool.

The surgical robotic system (four surgeon-controlled operating 'arms') was introduced via Earth Medical to four private hospitals in Cape Town, Johannesburg and Pretoria and gives highly skilled, appropriately trained specialists greater vision, precision and control during procedures, going beyond the flexibility and rotational capabilities of the human hand. It has also highlighted innate hospital/doctor and funder tensions in providing expensive but effective hightech medical equipment while maintaining viable patient funding. However, and perhaps most importantly, the da Vinci system has exposed an 'elephant in the room' - the internationally aberrant overuse by SA specialists of brachytherapy as a treatment modality for prostate cancer (73\% above the global norm). Funded as a prescribed minimum benefit by medical aids (as is open prostatic surgery and traditional keyhole surgery), brachytherapy (the relatively quick and highly strategic placement of a radioactive 'pellet' at the prostate cancer site) allows urologists to conduct twice as many procedures a day as is possible with open or laparoscopic surgery.

\section{Top academic compares} treatments - and backs the device

Top academic and urologist Prof. André van der Merwe of Stellenbosch University conducted an in-depth comparative literature study of the available treatment modalities for prostatic cancer in SA. He concluded that brachytherapy 'should be reduced to international proportions (i.e. to $7 \%$ from the SA usage figure of $80 \%$ ), with robotic laparoscopic surgery a 'valuable tool' in helping achieve this. In his paper, he neutrally comments that should the caring physician benefit from one of the many options, then he might be biased in the manner he counsels the newly diagnosed patient', adding that a powerful differential exists between the urologist and the patient in consultations after a diagnosis of prostate cancer is made. Izindaba interviews with well-placed expert sources gleaned anecdotal evidence that some urologists often fail to discuss the pros and cons of various therapeutic options with their patients (most have very similar eventual outcomes), pushing brachytherapy and often not mentioning the sometimes appropriate strategy of 'watchful waiting' and active surveillance. Dr Jonathan Broomberg, CEO of SA's largest open medical aid, Discovery Health, said it was 'critical' that doctors discuss all available treatment options and the associated risks and benefits with their patients. Patient choice and decisions based on best evidence were 'vital if we are to achieve better value in our healthcare system'

Van der Merwe described robotic surgery in SA as 'a major step forward in patient care' and 'the beginning of a new chapter in local healthcare. He concluded that even though it is unfair to compare the early learning curve

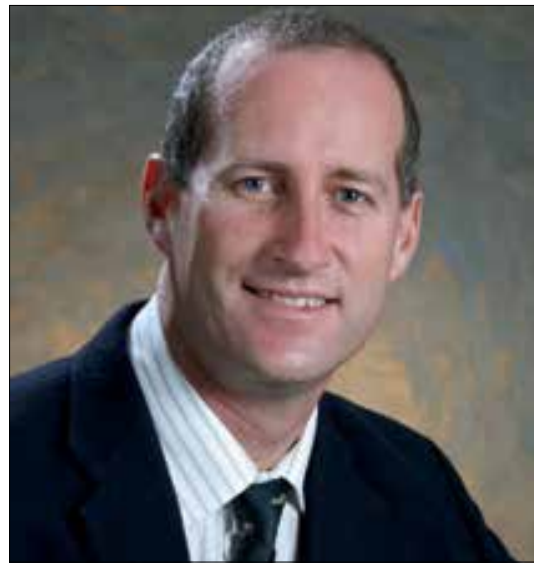

Prof. André van der Merwe.

of robotic prostatectomy with the established learning curve of open and laparoscopic radical prostatectomy, 'one could confidently say that the oncological (and urinary/sexual) outcomes are similar or better (using the da Vinci system), but definitely not worse'. Most importantly, properly performed, the camera-assisted robotic procedure is the international gold standard in minimally invasive surgery, halving recovery times and enabling unprecedented vision, precision and control (the 3-D HD camera image is magnified 10 times).

\section{As good as its operator}

The da Vinci, while an amazing piece of technology, is still a doctor-driven device. Training is taken very seriously, with doctors taught via a console-driven simulator where a $90 \%$ pass rate on 35 different test areas is required for hands-on proficiency. They are then sent to Belgium for live porcine practice. Following 
that, a highly experienced international urologist is flown out to SA to mentor the local urologists on patients via a 'buddy system. This involves two local urologists conducting a daily prostatectomy each for 10 days under supervision, the one local urologist observing and the other operating, and then swapping around in morning and afternoon sessions. This is obviously not teaching the urologist how to do a prostatectomy, but how to apply the da Vinci technology best to benefit from its advantages. The mentor may take over the console from time to time, just as a flying instructor would if potential safety concerns arise. Only when he is satisfied that they can use it safely and proficiently does he sign them off and they can go solo. Mentors insist that all procedures are filmed via the internal camera and e-mailed to them for ongoing monitoring and feedback, and they are continually available for advice and guidance. The average training time to full proficiency can vary from surgeon to surgeon. Simulator and initial local training takes some 45 hours and the overseas 'wet lab' training about 16 hours, while the local mentored stint typically covers 12 - 15 cases. Depending on the surgeon's skill levels and how quickly he or she gets the cases done, they may be spread out over between 3 months and a year, depending on a number of logistical factors. Newly signed-off urologists are counselled about the critical importance of patient selection, with obese patients initially avoided at all costs.

\section{Wider application imminent}

If the hospital and its doctors follow the proper surgery protocols, operations are safe, reproducible and result in reduced complications, minimal blood loss and improved functional and oncological outcome. According to Earth Medical, the rigorous training pathway eliminates any 'short cuts. Future applications for da Vinci surgery in SA would include appropriate colorectal and gynaecological procedures, and with over a year of successful use in prostatectomies, the intention is to move to other urological procedures including partial nephrectomies and and cystectomies.

One local hospital manager who has overseen the da Vinci introductory phase is Hein Calitz, general manager of Durbanville's Mediclinic Hospital. Quizzed on the health economics, Calitz said an entire operation cost about ZAR190 000 (including doctor and allied professionals' fees), of which they could recover only about ZAR125 000 - 135000 from some of the medical aids. However, certain medical aid schemes would only pay for open surgery and brachytherapy, flatly refusing to fund robotic surgery. 'At present we're writing that da Vinci medical aid payment shortfall off. We're not recovering from the patient yet. We're still crunching the numbers. It's for now more important to do volumes to get the surgeons fully trained than worry about getting a better price than ZAR125K and/or the balance in patient co-payments.' He intimated that over time, doctors would try and convince patients that it was worth their while to pay in the ZAR65 000 shortfall, although this could be phased in with patients paying half of this amount for the next year. Calitz said that the robot system was as susceptible to advancing technology as any other computer device, so that within $5-6$ years it would probably need replacing. His hospital group had built ZAR40 000 into the overall procedure price to recover some of the equipment expense. Calitz said when Mediclinic motivated for higher medical aid payouts for its robotic prostatectomies, the medical aids' response was that this would require an unrealistic increase in membership, or premium hikes, to make it financially viable. He said that punting procedure volumes, potentially improved surgical outcomes and vastly reduced patient recovery times cut no ice with medical aids, challenged as they already were by soaring new technology costs.

Broomberg told Izindaba that Discovery Health had performed a detailed health economic analysis on the use of the da Vinci robotic system for prostatectomy. Based on this, they funded the da Vinci robotic prostatectomy up to a 'defined rand limit', which was currently at a $40-60 \%$ premium over the cost of the open prostatectomy procedure. 'Our analysis indicates that this premium is the maximum that can be justified in terms of the incremental benefit of the da Vinci system, and also represents a sufficient reimbursement to the hospitals for the cost of the device. We've agreed a full reimbursement arrangement with some hospitals, but unfortunately, other hospitals insist on charging patients a higher rate, resulting in co-payments for some patients.'

Koert Pretorius, CEO of Mediclinic, said his company viewed the da Vinci system as research and development and a way of exposing doctors to the best research and technology while giving patients access to the latest treatment modalities. 'In principle we're prepared to make a contribution in the introductory phase, it's not just about money for us', he said.

\section{Chris Bateman}

chrisb@hmpg.co.za

S Afr Med J 2015;105(3):435-436.

DOI:10.7196/SAMJ.9464

\section{Case study: COPIC}

COPIC is a doctors' insurer based in Colorado, USA. They operate an in-house reporting system called the 'Three Rs' programme (Recognise, Respond, Resolve), where any doctor who has experienced an adverse outcome or had their patient express dissatisfaction with their care can contact a specific COPIC administrator to arrange their intervention. According to the COPIC website, the goals of the programme are 'to maintain the physician-patient relationship, facilitate open and honest communication and disclosure, and reimburse the patient for related out-of-pocket medical expenses.' ${ }^{\prime[1]}$

A series of interviews with patients who had participated in the programme revealed, tellingly, that: 'When the communication with the physician was good, open, and honest, the outcome was viewed as an honest mistake. Patients referred to their outcomes under these circumstances as both forgivable and understandable. Conversely, when the communication was perceived as poor or non-existent, the same outcome was viewed as an error or negligence.'[2]

Of the 1829 patients who had received reimbursement of their medical expenses through the programme, only $3.4 \%$ went on to make a claim against their doctor. While not officially described as a complaints system, COPIC's programme is an example of dissatisfaction handled effectively with a demonstrable effect on the likelihood of litigation.

1. www.callcopic.com/copic-services/safety-and-risk/Pages/3rs.aspx (accessed 7 October 2014).

2. Lembitz A. Litigation alternative: COPIC's 3Rs program. AAOS Now 2010;4(9). www.aaos.org/news/aaosnow/sep10/managing7.asp (accessed 5 May 2015). 

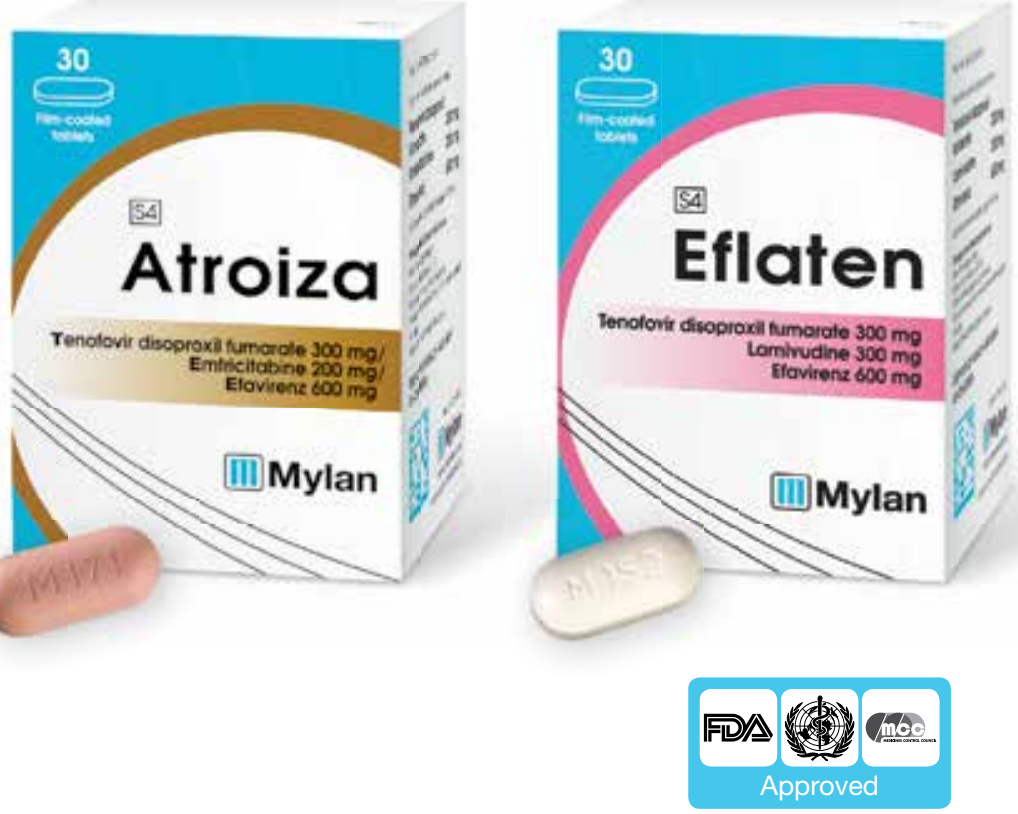

MYLAN ARVS, CONNECTING WITH \& TOUCHING

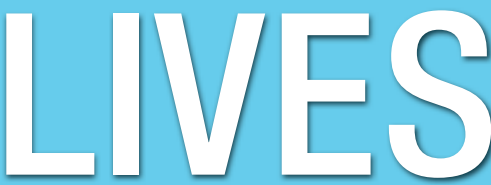

Convenience, improved adherence and efficacy all in one ${ }^{1}$

Mylan offers 2 triple fixed dose combinations for first line treatment ${ }^{2}$

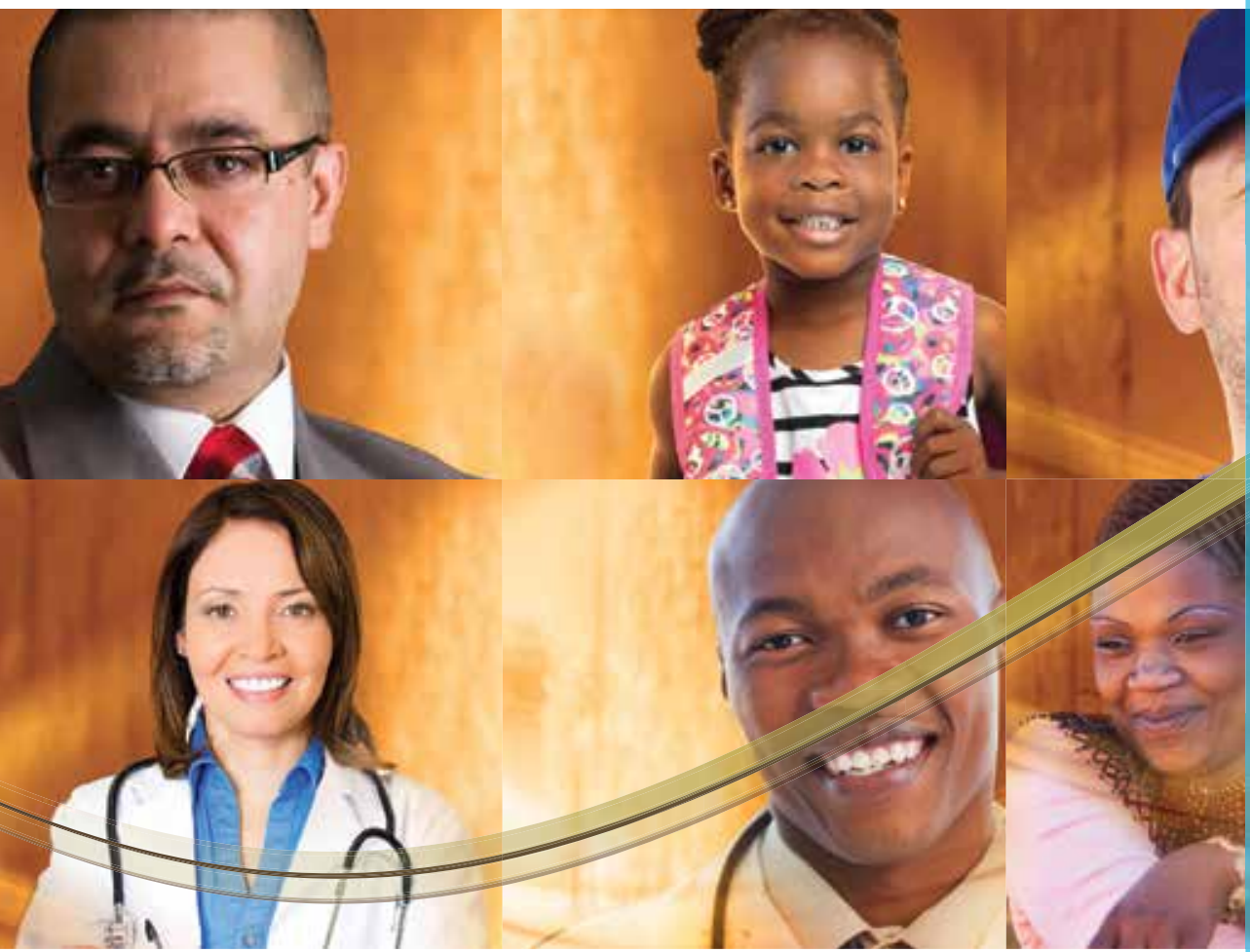

References: 1. Davies, N. Advice Document: Fixed dose combination for adults accessing antiretroviral therapy (Southern African HIV Clinicians Society). S Afr J HIV Med. 2013;14(1 Suppl):41-43. 2. Meintjes G, Maartens G, Boulle A, et al on behalf of the Southern African HIV Clinicians Society. Guidelines for antiretroviral therapy in adults. S Afr J HIV Med. 2012;13(3):114-133.

S4 ATROIZA (Film-coated tablets). Reg. No.: 45/20.2.8/0172. Each film-coated tablet contains tenofovir disoproxil fumarate $300 \mathrm{mg}$, efavirenz $600 \mathrm{mg}$ and emtricitabine $200 \mathrm{mg}$. Lactose monohydrate $120 \mathrm{mg}$.

S4 EFLATEN (Film-coated tablets). Reg. No.: 45/20.2.8/0171. Each film-coated tablet contains tenofovir disoproxil fumarate $300 \mathrm{mg}$, lamivudine $300 \mathrm{mg}$ and efavirenz $600 \mathrm{mg}$. Lactose monohydrate $60 \mathrm{mg}$

Mylan (Pty) Ltd. Reg. No.: 1949/035112/07. Building 6, Greenstone Hill Office Park, Emerald Boulevard, Modderfontein, 1645. Tel: (011) 451 1300. Fax: (011) 4511400.

For full prescribing information refer to the package insert approved by the medicines regulatory authority. M0632 May-15. 